\title{
Anatomy and Morphology of Two Hawailan Endemic Portulaca Species
}

*Correspondence to: Kim IS,

Tel: +82-53-580-5305

Fax: +82-53-580-5305

E-mail: botany@kmu.ac.kr

Received May 27, 2014

Revised June 21, 2014

Accepted June 23, 2014

(1)

In this study, the vegetative and reproductive morphology and anatomy of two Hawaiian endemic Portulaca species were examined. Specifically, P. molokiniensis and P. sclerocarpa were compared to closely related species in the genus. The comparisons were both qualitative and quantitative, using characteristics of leaves, stems, roots, and fruits. Tissue organizations of vegetative and reproductive parts of the plants were assessed using microtechnique procedures, statistical analysis, and scanning electron microscopy. The most notable features of these two species were (1) the size and frequency of stomata in P. molokiniensis, and (2) the large number of sclerenchymatous cell layers in the thickest fruit walls of $P$. sclerocarpa. These findings may imply that stomata development in $P$. molokiniensis and thick fruit wall development in P. sclerocarpa are evolved features of survival. In particular, the development of thickened walls in indehiscent fruits likely has evolutionary implications of ecological tolerance for better adaptation.

Key Words: Anatomy, Hawaiian Portulaca, Morphology, Secondary feature, Adaptation

\section{INTRODUCTION}

The genus Portulaca is known to withstand harsh environments with its various vegetative and reproductive features. Hawaiian Portulaca species are annual or perennial herbs that rarely form shrubs. Both native and introduced Portulaca species on the Hawaiian Islands, such as P. oleracea and P. pilosa, are relatively common. However, endemic species of $P$. molokiniensis and $P$. sclerocarpa are also present although not as widespread.

Among Hawaiian Portulaca species, P. molokiniensis and $P$. sclerocarpa have drawn attention because of their unusual vegetative and reproductive features. The relationship between these two species and other Portulaca species has been investigated in previous studies (Kim \& Carr, 1990a, 1990b). P. oleracea and P. pilosa, which is widely distributed, have particularly been of focus. This is because P. oleracea has been speculated to be the parental lineage of $P$. molokiniensis, and P. pilosa that of P. sclerocarpa (Yun, 1989; Wagner et al., 1999). Artificial, interspecific pollinations have yielded a hybrid between the broad-leaved $P$. molokiniensis $(2 \mathrm{n}=40)$ and P. oleracea $(2 \mathrm{n}=54)$ suggesting a close affinity and polyploid nature (Kim \& Carr, 1990a). Kim and Carr (1990a) have distinguished two groups of Hawaiian Portulaca species based on their chromosome ploidy level-polyploids $(2 n=40,54)$ in broad-leaved species versus diploids $(2 \mathrm{n}=18)$ in cylindricalleaved species. Reproductive features have been reported with variation among taxa in studies examining the reproductive biology and uniformity of Portulaca species (Kim \& Carr, 1990b) as well as their cytogenetics and hybridization (Kim \& Carr, 1990a). Furthermore, the Kranz anatomy, as in C-4 syndrome, has been well-demonstrated in a study investigating structural aspects of the leaves of seven Portulaca species growing in Hawaii (Kim \& Fisher, 1990). In recent works, morphological and anatomical features of seeds (Kim, 2012) and pollen grains (Kim, 2013) have revealed important structural patterns among taxa. None of these studies, however, include vegetative stomata features or other features that may have been influenced by polyploidy. Thus,

(a) This is an open-access article distributed under the terms of the Creative Commons Attribution Non-Commercial License (http://creativecommons.org/licenses/by-nc/3.0) which permits unrestricted noncommercial use, distribution, and reproduction in any medium, provided the original work is properly cited.

Copyrights (C) 2014 by Korean Society of Microscopy 
the present study highlights morphological and anatomical features of endemic Hawaiian Portulaca species such as these that may be of phylogenetic value.

\section{MATERIALS AND METHODS}

Approximately three to five plants of P. molokiniensis, P. lutea, P. oleracea, P. pilosa, P. villosa, and P. sclerocarpa were used for anatomical and morphological examinations. In case of the stomatal data collection, leaf samples gathered from several to more than ten individual plants were used. Fresh tissue samples were obtained from mature plants for the collection of qualitative and quantitative data. For anatomical examination, the leaves, stems, and roots of the plants were processed using microtechnique procedures employed by Cutler et al. (2008) although with some modifications. The samples were fixed for 12 to 24 hours in $6 \%$ glutaraldehyde. Then, they were dehydrated in a graded series of ethyl alcohol-tertiary butyl alcohol solutions, infiltration with parawax, and embedding in paraplast. Sections were made in $3 \sim 5 \mu \mathrm{m}$ of thickness, overstained with $1 \%$ safranin, and then counterstained with fast green. They were also fixed with $2 \% \sim 4 \%$ glutaraldehyde at room temperature, washed in 0.1 mol sodium phosphate buffer ( $\mathrm{pH}$ 7.2) three times, and embedded in Spurr's resin. Electron microscopy procedures were used with sections $1 \sim 2 \mu$ m thick.

Dehydrating the fixed samples in a graded series of acetone was followed by critical point drying with liquid carbon dioxide (Emitech K850; Emitech Ltd., UK). Processed samples were then mounted directly onto stubs using double-sided adhesive tape and coated with gold/palladium in a sputter coater (Emitech K550X; Emitech Ltd.). The samples were examined with Hitachi S-4200 scanning electron microscope at the Daegu Center of Korea Basic Science Institute in Daegu, South Korea.

Quantitative data on ten morphological and anatomical features were collected and statistically analyzed. These data were those concerning stomatal frequency $\left(\mathrm{no} / \mathrm{mm}^{2}\right)$ and size (length $\times$ width, $\mu \mathrm{m}$ ) in adaxial and abaxial surfaces, capsule size (length $\times$ width, $\mathrm{mm}$ ), ovary wall thickness $(\mu \mathrm{m})$, and number of seeds per capsule. These data were used especially in the descriptions and/or recognition of the two endemic species. For comparisons among taxa, statistical analyses of a multiple range test (Waller-Duncan test, ANOVA) and a t-test using the SAS program (SAS Institute, USA) were performed. Statistically significant differences were reported with a probability less than $0.05(\mathrm{p}<0.05)$. The WallerDuncan test was used to establish groups among endemic and related species. The $\mathrm{t}$-test was used to compare characteristics between the two taxa. All values stated for a given attribute in this paper represents mean values that were obtained during basic statistical analyses.

\section{RESULTS AND DISCUSSION}

\section{Gross Morphology}

All Portulaca species that were examined were succulent to various degrees in terms of their leaves, stems, and roots. At the tissue level, stomata were found in all green tissues throughout the plants (Fig. 1A and B) with development of copious prostate or erect branches (Fig. 1C and D). On axils of the leaves, node, and capitulum, axillary hairs were also present (Fig. 1E). The stems were mainly herbaceous with a periderm, cortex, vascular bundle, and pith. A certain degree of variation was found in the arrangement of vascular bundle in the stems with bundles sometimes extending deeply into the pith (Fig. 1F). They were hardly woody except at their bases. However, the thickest stem, which was found in P. molokiniensis, demonstrated a tetrarch arrangement of vascular bundles (Fig. 1G). This was likely due to decussate phyllotaxy and the presence of four leaf traces on the stem axis. On the other hand, the thinnest stem, found in P. pilosa (Fig. 1H), displayed a typical stem structure as in other Hawaiian Portulaca species. The roots were shallow and tuberous, but adventitious roots formed readily after injury or on stem cuttings in contact soil. All examined species had one to several tuberous roots (Fig. 1H); this has been considered an advanced characteristic (Carolin, 1987). A well-developed vascular bundle surrounding the entire pith, especially within highly tuberous roots, was noticed as in P. molokiniensis (Fig. 1I).

\section{Stomata}

The present study revealed various characteristics of stomata, such as their pattern, occurrence, distribution, and size. In all examined species, stomata were dispersed over the entire epidermis. They were located on the same level as both adaxial and abaxial epidermal cells. As illustrated in Fig. 1A and B, the stomata were paracytic (Cutler et al., 2008; Lee, 2012) with an alternating complex of three or more C-shaped subsidiary cells of graded sizes parallel to guard cells (Evert, 2006).

However, considerable variations were also noted in stomatal distribution and size. In general, stomata were more numerous on the abaxial surface than on the adaxial surface. The lowest density of adaxial and abaxial stomata was found in the largest-leaved P. molokiniensis. In this species, there were 19.6 stomata $/ \mathrm{mm}^{2}$ on the adaxial surface and 6.4 stomata/ $\mathrm{mm}^{2}$ on the abaxial surface. Furthermore, relatively large stomata were found on both surfaces in this species. The size of adaxial stomata averaged $53.7 \times 41.0 \mu \mathrm{m}$ (length $\times$ width) while abaxial stomata averaged $53.4 \times 41.2 \mu \mathrm{m}$. The highest adaxial and abaxial stomata were 49.3 and 29.0, respectively. The smallest stomata were found in P. pilosa where the adaxial and abaxial stomata were $33.8 \times 21.4 \mu \mathrm{m}$ and $30.4 \times 19.0$ $\mu \mathrm{m}$ in size respectively. Other taxa exhibited intermediacy in frequency and size of adaxial and abaxial stomata. The 
Table 1. Comparison of stomata characteristics in Hawaiian Potulaca (P.) species examined

\begin{tabular}{|c|c|c|c|c|c|c|c|c|c|c|c|c|}
\hline \multirow{2}{*}{ Taxon } & \multicolumn{2}{|c|}{ AD St $(\mu \mathrm{m})$} & \multicolumn{2}{|c|}{ W/D } & \multicolumn{2}{|c|}{$\mathrm{AB} S t(\mu \mathrm{m})$} & \multicolumn{2}{|c|}{$\mathrm{W} / \mathrm{D}$} & \multirow{2}{*}{ AD St FQ } & \multirow{2}{*}{$\mathrm{W} / \mathrm{D}$} & \multirow{2}{*}{ AB St FQ } & \multirow{2}{*}{$\mathrm{W} / \mathrm{D}$} \\
\hline & $\mathrm{L}$ & $\mathrm{W}$ & $\mathrm{L}$ & $\mathrm{W}$ & $\mathrm{L}$ & $\mathrm{W}$ & $\mathrm{L}$ & $\mathrm{W}$ & & & & \\
\hline P. oleracea & 44.7 & 31.2 & $\mathrm{C}$ & $\mathrm{C}$ & 49.5 & 35.9 & B & $\mathrm{B}$ & 35.7 & $\mathrm{C}$ & 15.9 & $\mathrm{D}$ \\
\hline P. lutea & 50.9 & 36.9 & B & B & 52.0 & 38.9 & A & A & 25.5 & D & 11.4 & E \\
\hline P. molokiniensis & 53.7 & 40.0 & A & A & 53.4 & 41.2 & A & A & 19.6 & E & 6.4 & $\mathrm{~F}$ \\
\hline P. pilosa & 33.8 & 21.4 & $\mathrm{EF}$ & G & 30.4 & 19.0 & G & G & 40.9 & B & 21.1 & $\mathrm{C}$ \\
\hline P. villosa & 41.2 & 24.5 & $\mathrm{D}$ & $\mathrm{DE}$ & 36.5 & 23.5 & $\mathrm{C}$ & $\mathrm{C}$ & 24.9 & D & 19.7 & $\mathrm{C}$ \\
\hline P. sclerocarpa & 35.9 & 21.9 & $\mathrm{EF}$ & FG & 37.6 & 22.6 & $\mathrm{D}$ & $\mathrm{DE}$ & 25.4 & $\mathrm{D}$ & 21.1 & $\mathrm{C}$ \\
\hline
\end{tabular}

$\mathrm{AD}$, adaxial; St, stomata; $\mathrm{W} / \mathrm{D}$, Waller-Duncan test; $\mathrm{AB}$, abaxial; $\mathrm{L}$, length; $\mathrm{W}$, width; $\mathrm{FQ}$, frequency.

Mean values with the same letter are not significantly different in analysis of variance.
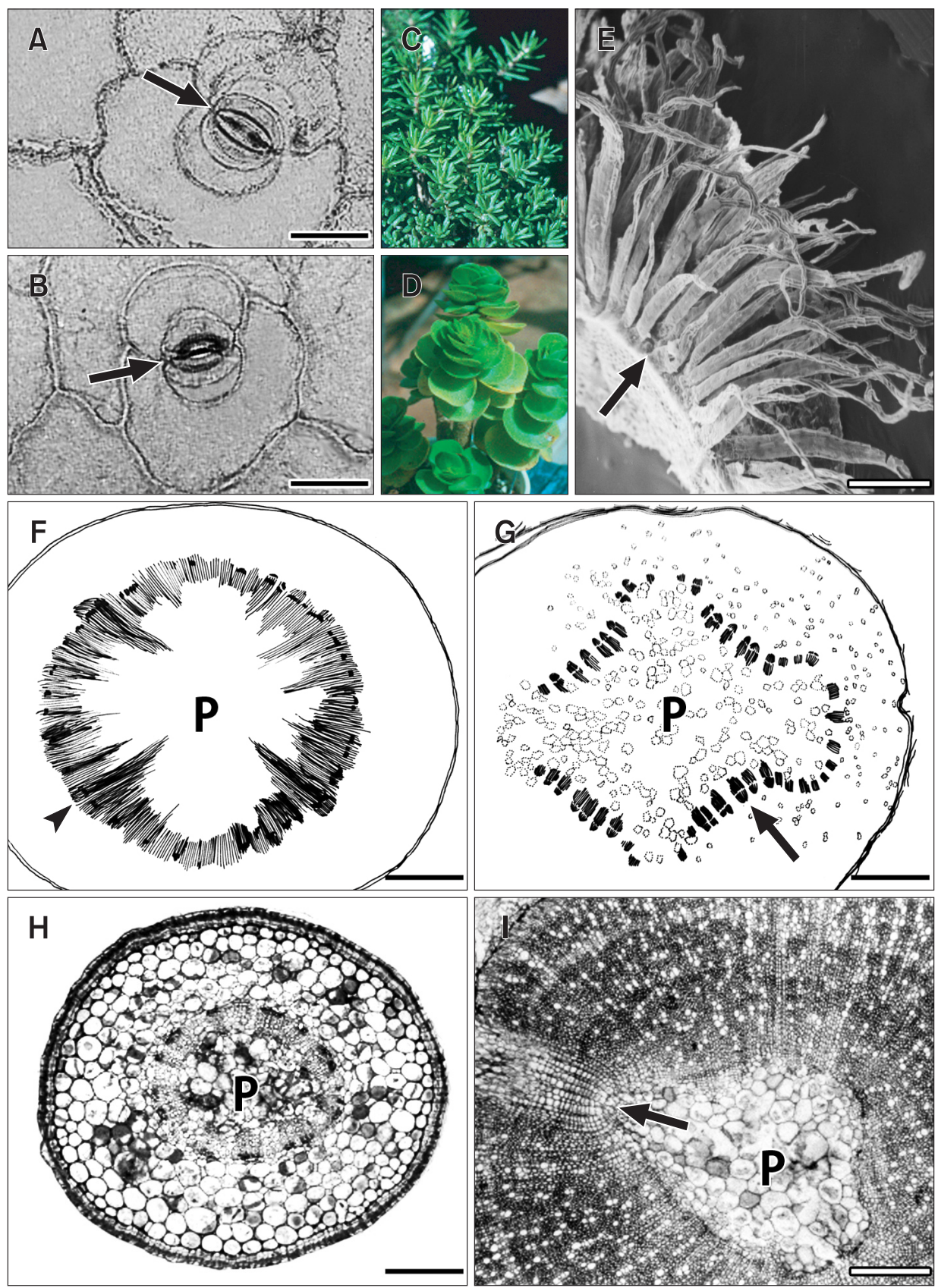

Fig. 1. Anatomy and morphology of Portulaca species. $1 \mathrm{~F}$ and $1 \mathrm{G}$ are line drawings made out of the micrographs. (A, B) Paracytic stomata in P. molokiniensis. (A) Adaxial stomata (arrow). Scale bar $=50$ $\mu \mathrm{m}$. (B) Abaxial stomata (arrow). Scale bar $=50 \mu \mathrm{m}$. (C) Branches of $P$. sclerocarpa. (D) Leaves of P. molokiniensis. (E) Axillary hairs (arrow) in P. molokiniensis. Scale bar $=500 \mu \mathrm{m}$. (F-H) Cross sections of stem in P. lutea (F, scale bar $=2 \mathrm{~mm}$; an arrowhead indicated vascular bundles), P. molokiniensis ( $\mathrm{G}$, scale bar $=3 \mathrm{~mm}$; an arrow indicated tetrarch pattern), and $P$. pilosa $(\mathrm{H}$, scale bar $=500 \mu \mathrm{m})$. (I) Cross section of root in P. molokiniensis (scale bar $=500 \mu \mathrm{m})$. An arrow indicated the lateral root formation. P, pith. 
Waller-Duncan test performed on the size of these stomata indicated a significant difference among the species compared (Table 1). A range of morphological divergence associated with differences in ploidy level that are found in numerous plant groups (Stace, 2000) can be applied similarly to $P$. molokiniensis exhibiting polyploidy (Kim \& Carr, 1990a) for increased stomatal size in this study.

\section{Fruits}

Most Hawaiian Portulaca species have a circumscissile capsule as their fruit type with a dehiscent operculum that occupies about $50 \%$ to $80 \%$ of the height of the fruit. The ratio between the height of the operculum and the total height of the fruit has been used as a distinguishing characteristic in Portulaca species. However, no clear delineation could be made by applying this feature to the Hawaiian species as most examined species had a ratio of $1 / 2 \sim 3 / 5$ in rather small capsules. Using this feature to distinguish endemic species has also been rejected as this ratio was not consistent or useful in most Portulaca species. Indehiscent capsules in P. sclerocarpa, however, have been considered an advanced feature in the fruit of this species (Stace, 2000).

In past studies, other characteristics such as operculum surface were also suggested to be distinguishing factors in certain species (Yun, 1989). However, this was not supported in this study because of the presence of both shiny and dull operculum in the given species. In terms of tissue structure and thickness of ovary walls (pericarp), the examined Portulaca species had one layer of epidermis and pericarp proper. The pericarp walls were made of sclerenchymatous cells and variously disintegrating mesophyll cells. No evidence of epicarp and/or endocarp differentiation was found in any of the sectioned materials.

Epidermal cells were elongated and their walls were thickened adaxially in general. The pattern and number of cell layers in the pericarp proper were somewhat different, although no further differentiation into exo-, meso-, and endocarp was found. The most frequently observed pattern was an arrangement of 1 2 layers of shriveled cells beneath a thick epidermis (Fig. 2A and B). The epidermal cells of the fruit were elongated in most species, but in $P$. molokiniensis both elongated and isodiametric cells were found. Elongated cells have been regarded an advanced, adaptive feature although the reversion from an elongated to isodiametric state has also been seen in the family (Carolin, 1987). A few layers of crushed cells were found beneath these layers. A similar
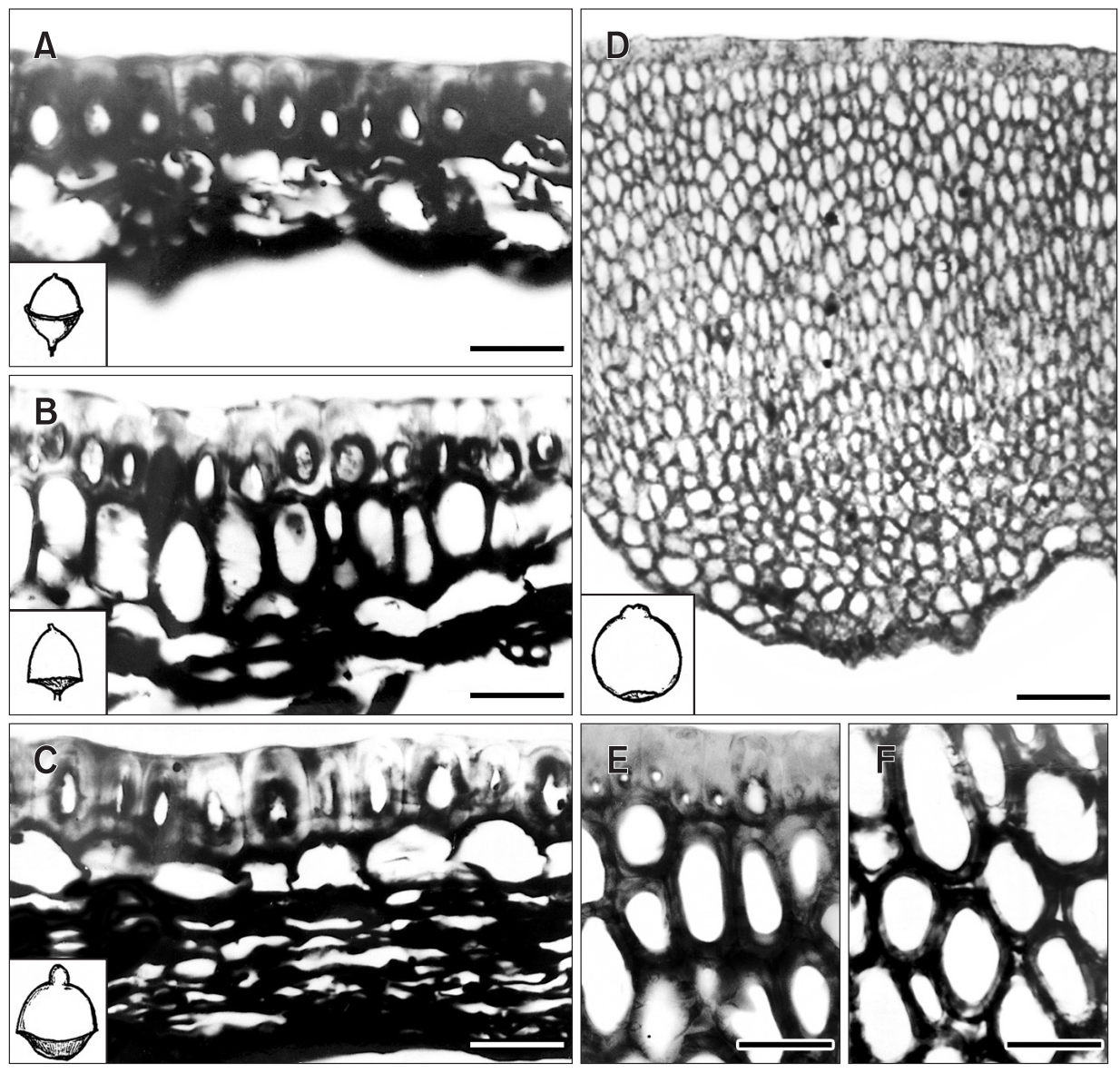

Fig. 2. Cross sections of ovary walls in Portulaca. An insert in each photograph indicated a capsule for the species. (A) $P$. pilosa. Scale bar $=30 \mu \mathrm{m}$. (B) P. villilosa. Scale bar $=30 \mu \mathrm{m}$. (C) P. molokiniensis. Scale bar $=30 \mu \mathrm{m}$. (D) P. sclerocarpa. Scale bar $=200 \mu \mathrm{m}$. (E) Close up view of the epidermal area from Fig. 2D. Scale bar $=30$ $\mu \mathrm{m}$. (F) Close up view of the sclerenchyma cells below the epidermis in Fig. 2D. Scale bar $=30 \mu \mathrm{m}$. Note the intact and thick cell wall in each cell boundary. 
pattern, albeit with many more crushed cell layers $(>10$ layers), were observed in P. molokiniensis (Fig. 2C). Uniformly thickened epidermal cell walls were found only in this species. The ovary epidermal cell height ranged from 19 to $24 \mu \mathrm{m}$, but slightly longer (about $36 \mu \mathrm{m}$ ) cells were formed in $P$. sclerocarpa.

The most unusual pattern was noted in P. sclerocarpa, whose prominent sclerenchyma cells occupied the entire pericarp proper (Fig. 2D-F). Approximately 25 to 30 layers of sclerenchyma formed the highly lignified ovary walls. The thickest walls $(369.5 \mu \mathrm{m})$ were found in P. sclerocarpa and the thinnest $(13.5 \mu \mathrm{m})$ in $P$. oleracea. In P. molokiniensis, the walls averaged $46.2 \mu \mathrm{m}$, while the rest of the taxa possessed relatively thin-walled ovaries, ranging from 26 to $37 \mu \mathrm{m}$. The thickest fruit walls, found in P. sclerocarpa, had a similar wall structure as in other species but showed a greater number of sclerenchymatous cell layers mostly without disintegrating mesophyll cell layers. The present study focused more on this feature, using it to distinguish $P$. sclerocarpa from other related species (Fig. 2A and B). The indehiscence fruit with an increased ovary wall thickness likely represent a relatively recent speciation of P. sclerocarpa in the Hawaiian Islands. Thickened walls in an indehiscent fruit may have developed in order to better adapt to harsh environments. Basic statistics concerning characteristics of the fruit wall are illustrated in Fig. 3.

Studies of seed morphology of the two endemic species and their possible parental lineages have revealed an atypical seed coat epidermal pattern (Yun, 1989; Kim, 2012). In $P$. molokiniensis (Fig. 4A and B) and some P. oleracea (Fig. 4C) of this study, epidermal cells in this seed coat were spinous or tuberculate (Fig. 4A). The numerous seeds were easily released when the operculum dehisced without any force from the capsule (Fig. 4D). Their spines and/or tubercles have been known to be hollow (Kim, 2012), but two layers of integument (inner and outer) delimited the seed proper from the seed coat. The seeds were large in P. molokiniensis and rather small in $P$. sclerocarpa, whose shiny surfaces were

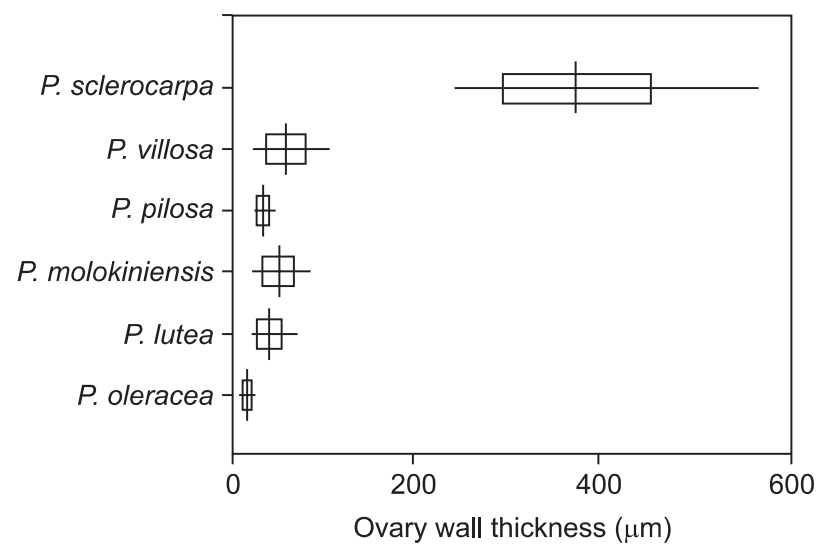

Fig. 3. Comparison of ovary wall thickness $(\mu \mathrm{m})$ of the examined Portulaca (P.).
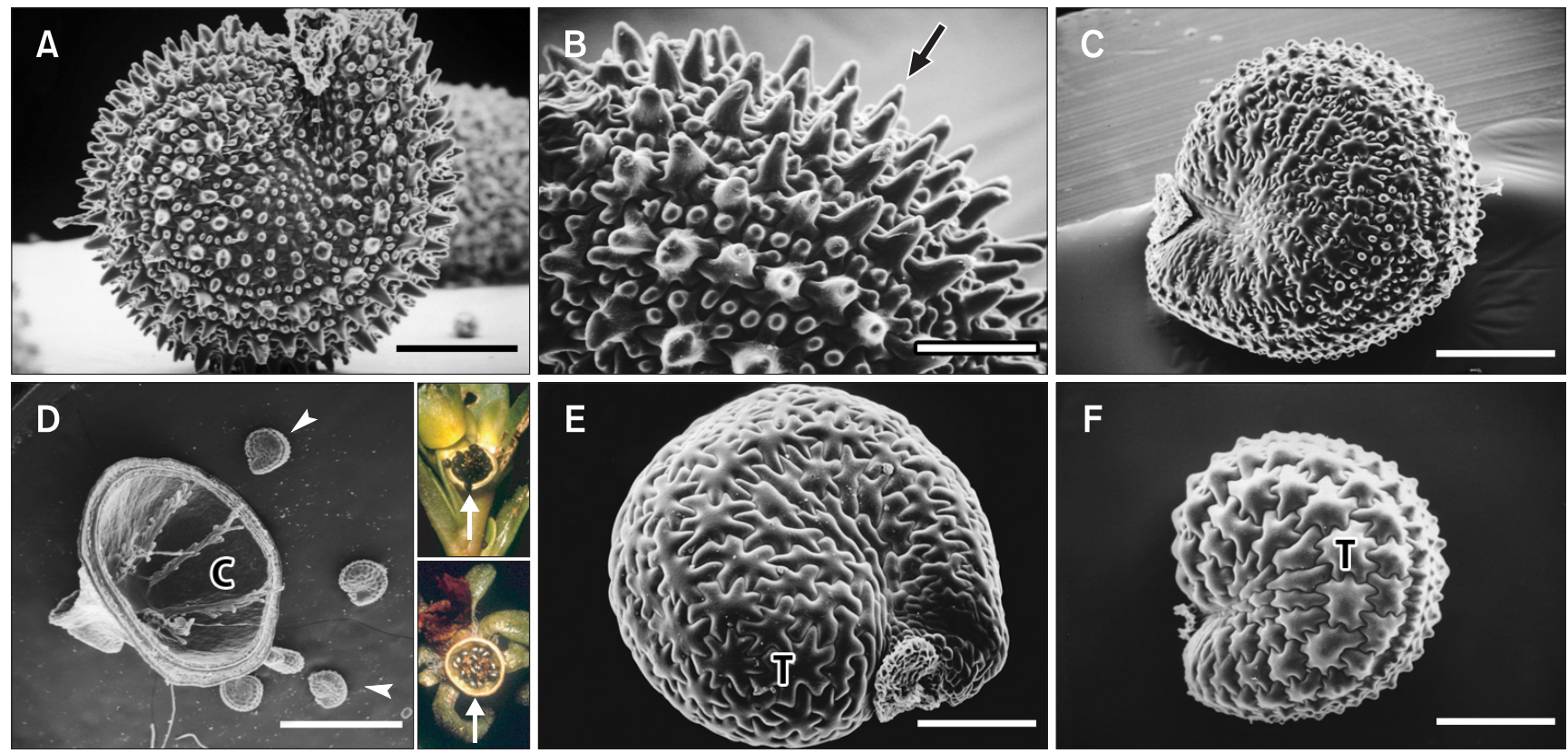

Fig. 4. Seed morphology of Portulaca. (A) P. molokiniensis. Scale bar $=500 \mu \mathrm{m}$. (B) Close up view of P. molokiniensis. An arrow indicated a spine. Scale bar $=100 \mu \mathrm{m}$. (C) P. oleracea. Scale bar=300 $\mu \mathrm{m}$. (D) Dehisced capsule with released seeds (arrowheads) in P. pilosa. Scale bar=1.5 mm. Insert (up): a capsule with just dehisced operculum in P. oleracea having numerous fresh seeds (arrow). Insert (bottom): a dry capsule in P. pilosa (arrow). (E) P. sclerocarpa. Scale bar $=200 \mu \mathrm{m}$. (F) P. pilosa. Scale bar $=100 \mu \mathrm{m}$. C, capsule; T, testa epidermal cell. 
smooth and flat (Fig. 4E). Seeds of the widely distributed P. pilosa exhibited tubercles with blunt-tips (Fig. 4F) like in non-Hawaiian species. Comparison of the present and earlier studies on Portulaca seeds generally supports the similarity within the family.

Seed morphology was compared among the examined species and was found to be useful in the recognition of the species and/or the genus (Matthews \& Levins, 1986; Kim \& Carr, 1990a; Matthews et al., 1992; Kim, 2012). However, the seed surface was found to vary to a small degree, although the focus of this study was the presence/absence and distribution of tubercles. The tuberculate nature was obvious in $P$. molokiniensis and P. oleracea. Up to $90 \mu \mathrm{m}$ elongated spines were found within endemic $P$. molokiniensis. The results of this study support the findings of other studies regarding seed ornamentation (Matthews et al., 1994; Kim, 2012). Having numerous, small seeds in a thick capsular ovary in $P$. sclerocarpa was speculated to be another adaptation technique to increase probability of finding an appropriate habitat for growth as in other small seeded species (Plaza et al., 2004).

Results obtained in this study support the idea that $P$. molokiniensis and P. oleracea come from one lineage, while P. sclerocarpa and P. pilosa come from another (Kim \& Carr, 1990a, 1990b; Baldwin \& Wagner, 2010). However, more research is needed for further confirmation. Phylogenetic and molecular investigations are needed to examine the endemic Hawaiian species and their putative ancestors or species that share a close affinity. New data from such research may provide a better understanding of the Hawaiian endemic
Portulaca species' lineage.

\section{CONCLUSIONS}

Tissue organizations of the leaves, stems, roots, and fruits of Portulaca species, including two Hawaiian endemic species, were assessed in this study using microtechnique procedures, statistical analysis, and scanning electron microscopy. Among the examined species, $P$. molokiniensis, and $P$. sclerocarpa were identified as having distinct vegetative and reproductive features. For P. molokiniensis, stomata were distinguished from those of other species in their size and frequency. In addition, fruit walls in P. sclerocarpa were particularly thick, consisting of layers of sclerenchymatous cells. Such characteristics were supported by statistically significant differences revealed in the multiple range test. The findings of this study confirm the importance of stomatal characteristics in the identification of P. molokiniensis, as well as fruit features highlighting the separation of $P$. sclerocarpa from other related species. Thus, stomatal attributes in leaves and thickened walls in indehiscent fruits likely have evolutionary implications. The relatively large, lowest density stomata in P. molokiniensis and thickened fruit walls in P. sclerocarpa may be adaptive features with high ecological tolerance values.

\section{CONFLICT OF INTEREST}

No potential conflict of interest relevant to this article was reported.

\section{REFERENCES}

Baldwin B G and Wagner W L (2010) Hawaiian angiosperm radiations of North American origin. Ann. Bot. 105, 849-879.

Carolin R (1987) A review of the family Portulacaceae. Aust. J. Bot. 35, 383-412.

Cutler D F, Botha T, and Stevenson D W (2008) Plant Anatomy: An Applied Approach. pp. 170-191, (Blackwell Publishing, Oxford).

Evert R F (2006) Esau's Plant Anatomy. 2nd ed., pp. 225-230, (John Wiley \& Sons Inc., Hoboken).

Kim I (2012) Anatomical and morphological features of seeds in Portulaca. Appl. Microsc. 42, 194-199.

Kim I (2013) Morphological features of pollen grains in Portulaca. Appl. Microsc. 43, 75-80.

Kim I and Carr G D (1990a) Cytogenetics and hybridization of Portulaca in Hawaii. Syst. Bot. 15, 370-377.

Kim I and Carr G D (1990b) Reproductive biology and uniform culture of Portulaca in Hawaii. Pac. Sci. 44, 123-129.

Kim I and Fisher D G (1990) Structural aspects of the leaves of seven species of Portulaca growing in Hawaii. Can. J. Bot. 68, 1803-1811.

Lee K (2012) Plant Morphology. 2nd ed., pp. 83-84, (Life Science
Publishing Co., Seoul).

Matthews J F and Levins P A (1986) The systematic significance of seed morphology in Portulaca (Portulacaceae) under scanning electron microscopy. Syst. Bot. 11, 302-308.

Matthews J F, Ketron D W, and Zane S F (1992) The reevaluation of Portulaca pilosa and P. mundula (Portulacaceae). Sida 15, 71-89.

Matthews J F, Ketron D W, and Zane S F (1994) The seed surface morphology and cytology of six species of Portulaca (Portulacaceae). Castanea 59, 331-337.

Plaza L, Fernandez I, Juan R, Pastor J, and Pujadas A (2004) Micromorphological studies on seeds of Orobanche species from the Iberian Peninsula and the Balearic Islands, and their systematic significance. Ann. Bot. 94, 167-178.

Stace C A (2000) Plant Taxonomy and Biosystematics. 2nd ed., pp. 6985, (University of Cambridge Press, Cambridge).

Wagner W L, Herbst D R, and Sohmer S H (1999) Portulaca. In: Manual of the Flowering Plants of Hawaii. Vol. 2., pp. 1070-1075, (University of Hawaii Press, Honolulu).

Yun I K (1989) Biosystematics and ultrastructure of Portulaca in Hawaii. Ph.D. dissertation, (University of Hawaii at Manoa, Honolulu). 